\title{
THE MERSILENE COVERED INTRAORBITAL IMPLANT
}

\author{
J. D. HUGHES ${ }^{1}$, R. N. DOWNES ${ }^{1}$, E. KEMP ${ }^{2}$ \\ Aylesbury and Ayr
}

\begin{abstract}
SUMMARY
The most widely used material for covering spherical intraorbital implants is sclera. Mersilene mesh is an alternative substance combining the advantages of permanent implant cover with low rates of infection and ready availability. We describe our experiences in the use of Mersilene mesh covered intraorbital implants in 14 patients. Our findings suggest that Mersilene mesh could be considered as a possible alternative choice of material for covering intraorbital implants.
\end{abstract}

Advantages of encasing buried spherical intraorbital implants in a material such as sclera have been described. The extra layer provides a framework for attachment of orbital tissues and decreases the possibility of extrusion of the implant.

Sclera and fascia are widely used but their disadvantages include variable absorption and antigenicity, availability and pre-use screening for HIV virus and hepatitis B virus. The use of a non-absorbable macromesh, while still providing a permanent scaffold for fibrovascular ingrowth from orbital tissues, eliminates these problems. Mersilene mesh, an interwoven polyester fibre mesh, is such a material. Its use in other clinical situations such as a repair material for hernias and tissue defects in general surgery ${ }^{1}$ and as a tendon replacement substance in orthopaedic surgery, ${ }^{2}$ has been described. It has also been employed successfully in the orbital region as a ptosis sling ${ }^{3}$ and lid spacer. ${ }^{4}$ In this two-centre study Mersilene mesh has been used in 14 patients in such a way and the results, with a minimum follow-up of six months, are presented and discussed.

\section{MATERIALS AND METHODS}

Mersilene mesh was used to cover a spherical orbital implant in fourteen patients. Nine primary and five secondary implants were performed. Details of individual patients are given in Table I.

From: 'Department of Ophthalmology, Princess Mary's RAF Hospital, Halton, Aylesbury, Bucks HP22 5PS. 'Department of Ophthalmology, Heathfield Hospital, Heathfield Road, Ayr.

Correspondence to: $\mathrm{Mr} \mathrm{R}$. N. Downes, Department of Ophthalmology. Princess Mary's RAF Hospital, Halton, Aylesbury, Bucks HP22 5PS, UK.
A standard technique of enucleation was performed in primary cases and in secondary cases any previous implant was removed with conservation of as much tissue as possible to ensure adequate cover of the implant. ${ }^{5}$

The sterilised Mersilene mesh was thoroughly soaked in a broad-spectrum antibiotic suspension prior to application around the sphere. The mesh was wrapped around the sphere and sutured with 5/0 Ethibond as shown in Fig. 1-3. The implant was inserted with the sutured aspect facing posteriorly. The recti muscles, except superior rectus, were attached anteriorly to the mesh taking care to avoid excess tension. The implant was positioned posterior to Tenon's layer in all cases and Tenon's and conjunctiva were closed in separate layers to ensure adequate cover of the implant anteriorly, without forniceal compromise.

Post-operative topical antibiotics were routinely prescribed and oral antibiotics were given to nine of the fourteen patients.

\section{RESULTS}

To date, with a minimum follow-up of six months, 12 patients have retained their implants. Examples of patients with successful implants are shown in Figs. 4-6. Extrusion occurred in Case 7 at nine months post-operation, and in Case 11 recurrent fistula formation necessitated removal of the implant.

Partial extrusion of the implant occurred in one patient at one month post-operation and was repaired with a scleral patch. One patient suffered a minor superficial infection in the early post-operative period which settled with topical antibiotics. An excess of granulation tissue was excised in one patient at two months post-operation.

\section{DISCUSSION}

The advantages of replacement of globe volume with an implant following enucleation or evisceration surgery are well-described and include reduction of socket contraction post-operatively and greater mobility of the prosthesis. $^{6}$

There have been an enormous variety of orbital implants used since Mules first implanted glass spheres in 1884. In the 1940s and 1950s semi-buried implants became popular. All these contained some type of pro- 
Table I. Patient details

\begin{tabular}{|c|c|c|c|c|c|c|}
\hline & & Patient & & Reason for removal of eye & Implant & Size \\
\hline 1 & $\mathrm{JM}$ & $67 \mathrm{yrs}$ & $\mathrm{F}$ & Chronic simple glaucoma; blind painful eye & Secondary & $18 \mathrm{~mm}$ \\
\hline 2 & RT & 34 yrs & M & Congenital malignant glioma & Secondary & $16 \mathrm{~mm}$ \\
\hline 3 & $\mathrm{JM}$ & 81 yrs & $\mathrm{F}$ & Perforation of corneal ulcer; exudative detachment of retina and choroid & Primary & $18 \mathrm{~mm}$ \\
\hline 4 & NH & 6 yrs & $\mathrm{F}$ & Teratoma of the orbit & Primary & $16 \mathrm{~mm}$ \\
\hline 5 & $\mathrm{AMcW}$ & $61 \mathrm{yrs}$ & $\mathrm{M}$ & Choroidal malignant melanoma & Primary & $22 \mathrm{~mm}$ \\
\hline 6 & $\mathrm{JR}$ & 80 yrs & $\mathrm{F}$ & Expulsive haemorrhage during cataract extraction & Primary & $20 \mathrm{~mm}$ \\
\hline 7 & $\mathrm{CB}$ & 7 yrs & $\mathrm{F}$ & Ruptured globe caused by accidental trauma & Primary & $18 \mathrm{~mm}$ \\
\hline 8 & $\mathrm{AC}$ & 22 yrs & $\mathrm{F}$ & Neovascular glaucoma; blind painful eye & Primary & $20 \mathrm{~mm}$ \\
\hline 9 & PW & 48 yrs & M & Angle recession associated glaucoma; blind painful eye & Primary & $18 \mathrm{~mm}$ \\
\hline 10 & MH & $18 \mathrm{yrs}$ & M & Perforating injury from air gun pellet & Primary & $20 \mathrm{~mm}$ \\
\hline 11 & $\mathrm{JB}$ & $28 \mathrm{yrs}$ & M & Penetrating injury & Secondary & $20 \mathrm{~mm}$ \\
\hline 12 & MI & 78 yrs & $\mathrm{F}$ & Choroidal malignant melanoma & Primary & $20 \mathrm{~mm}$ \\
\hline 13 & MS & $50 \mathrm{yrs}$ & M & Glaucoma secondary to trachoma and penetrating keratoplasty & Secondary & $22 \mathrm{~mm}$ \\
\hline 14 & JS & $50 \mathrm{yrs}$ & M & Penetrating injury & Secondary & $20 \mathrm{~mm}$ \\
\hline
\end{tabular}

trusion that attached to the prosthesis. The motility of the prosthesis was excellent but because part of the implant was exposed infection often supervened with consequent high extrusion rates.

Designs of buried implants have differed widely, each with its own advantages. The Allen implant with tunnels

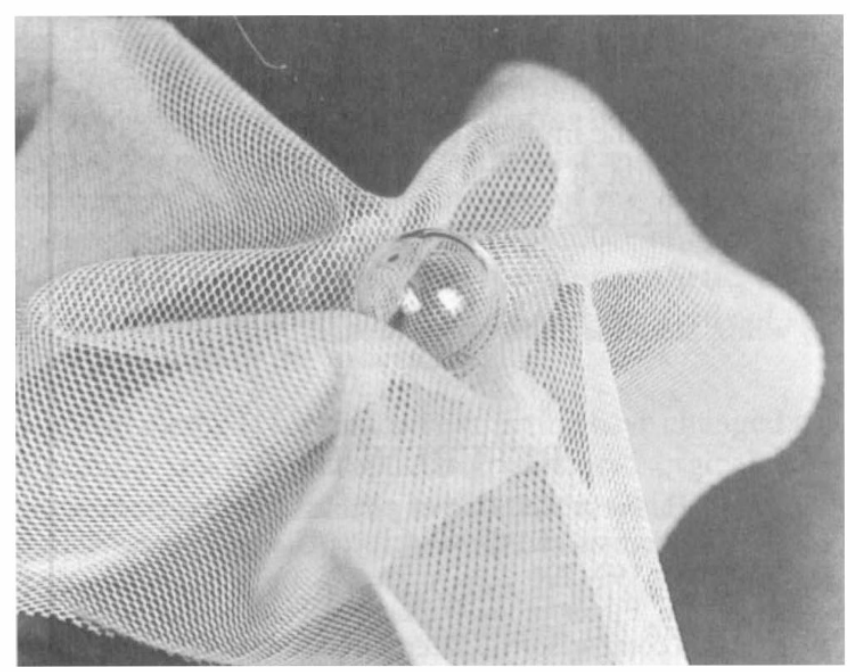

Fig 1.

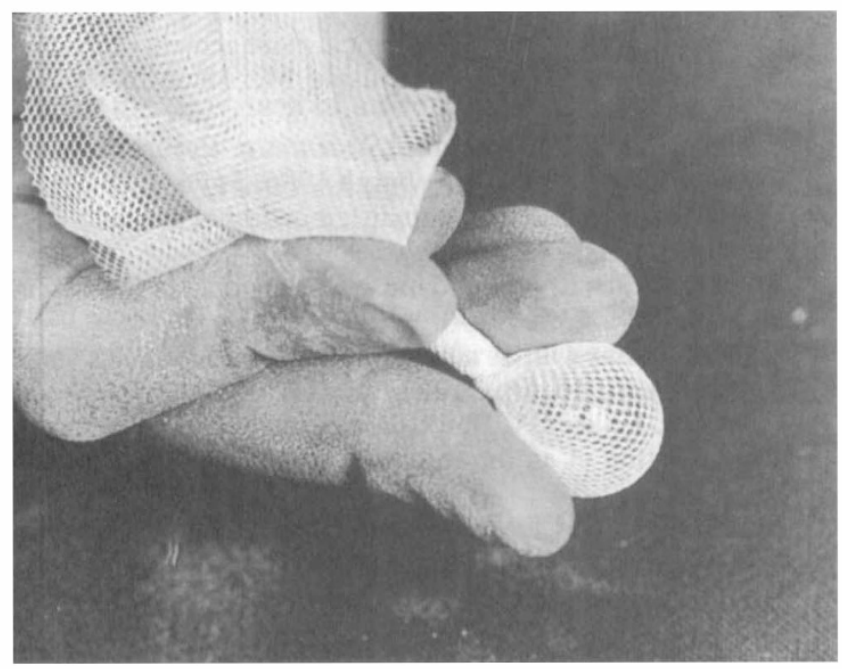

Fig 2. for extra-ocular muscles reduced implant migration; ${ }^{7}$ the magnetic implant using magnets on implant and prosthesis increased prosthetic motility. ${ }^{8}$ Frueh and Felker described the use of a baseball implant in the 1970s. ${ }^{9}$ This consisted of an acrylic ball enveloped in donor sclera which provided a framework for firm attachment of orbital tissues, reduced implant migration and provided an extra barrier against extrusion.

Sclera is now the most widely used material for spherical implants but it does have some disadvantages. The donor sclera should be screened for HIV and hepatitis B virus before use and may not be readily available. It excites variable inflammation and variably resorbs. ${ }^{10}$ Mersilene mesh combines the advantages of sclera with others of its own: it is easily prepared, inexpensive and can be used from the shelf. There is no need for pre-use viral screening and postoperative tissue inflammation is minimal. The success in lid surgery ${ }^{3,4}$ prompted its use as an alternative to sclera for covering spherical orbital implants.

The implant was quick and easy to prepare and insertion was aided by pre-use soaking of the mesh in an antibiotic solution. Wetting of the mesh reduced tissue drag on insertion. Early post-operative recovery was uneventful in all

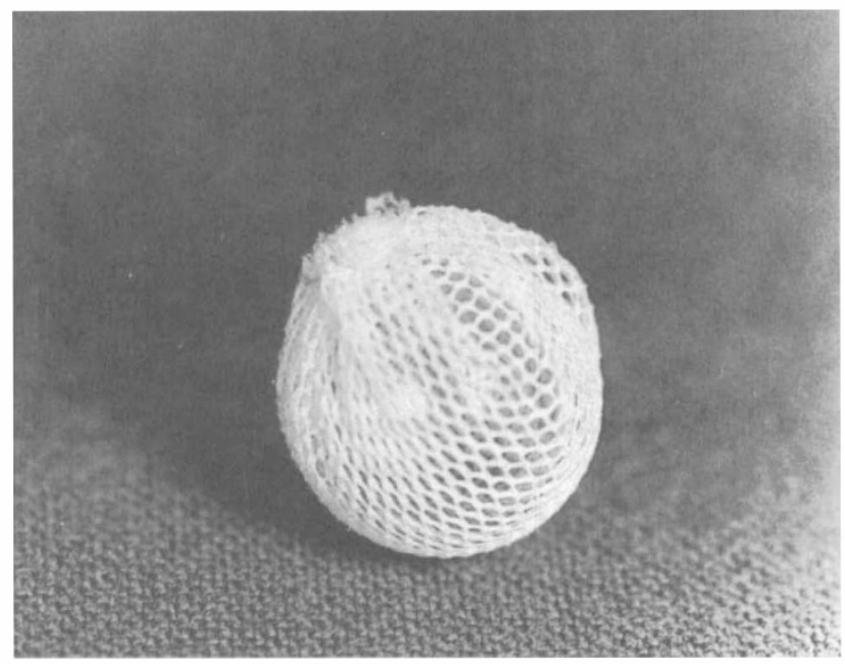

Fig 3.

Figs. 1-3. Method of enveloping orbital implant with the Mersilene mesh. 


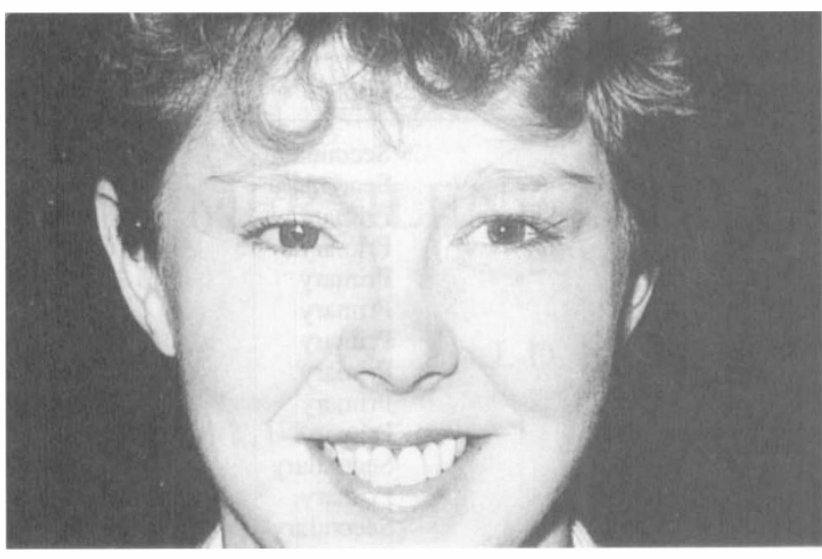

Fig. 4. Post-operative photograph of Case 8; a right-sided primary implant for a blind painful glaucomatous eye.

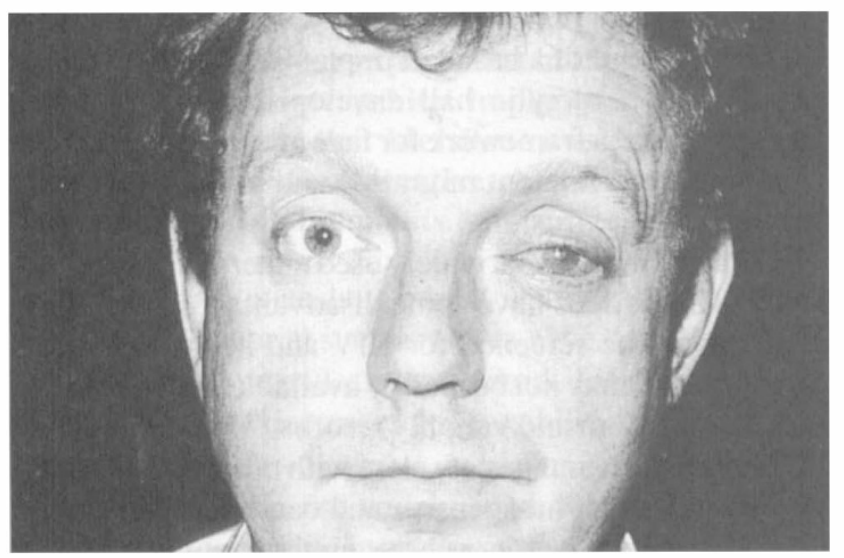

Fig. 5. Pre-operative photograph of Case 9; left sided primary implant for a blind painful eye due to angle-recession associated glaucoma.

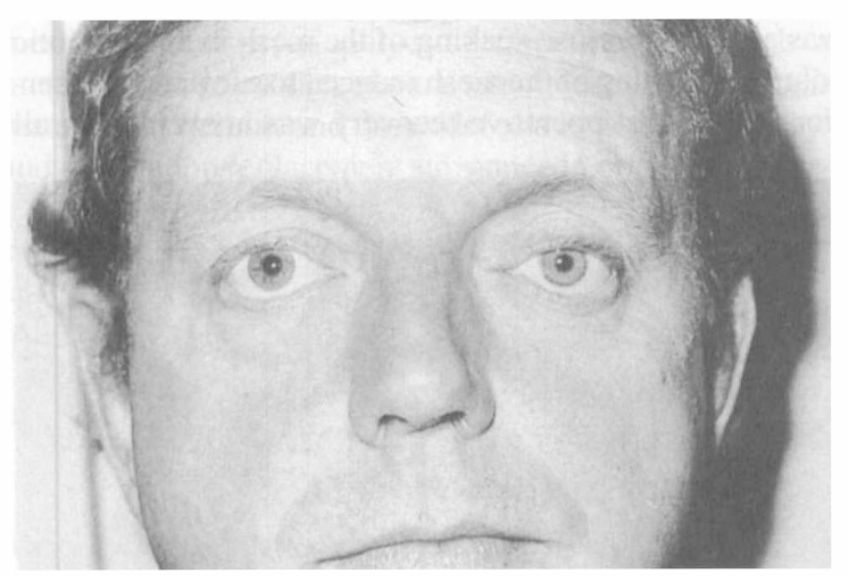

Fig. 6. Post-operative photograph of Case 9.

but one patient and associated with minimal tissue inflammation and discomfort. One patient suffered a mild superficial infection four days post-operatively which settled with topical gentamicin drops.

Extrusion in one patient (Case 7) may have been associated with the Mersilene mesh as histological examination demonstrated a giant-cell granulomatous picture. In this case the implant was a primary implant in a trauma case and oral antibiotics were not prescribed post-operatively.

Although the extrusion occurred nine months postoperatively care should be taken in using the mesh in trauma cases (a situation now recognised with all nonautogenous material), ${ }^{11}$ and oral antibiotics should be routinely prescribed post-operatively in all cases.

Recurrent fistula formation between implant and conjunctiva, probably related to inadequate conjunctival/ Tenon's cover necessitated removal of the implant in one patient (Case 11). Inadequate conjunctival cover also accounted for one case (Case 1) of partial extrusion which was repaired successfully with a scleral patch at one month post-operation. In one patient with a secondary implant an excess of granulation tissue developed which was excised uneventfully two months post-operation.

\section{CONCLUSIONS}

Although this series is small the results are encouraging and we feel that the Mersilene mesh covered spherical implant may be considered for use in primary and secondary implants taking care with its choice in trauma cases. We recommend pre-use soaking of the mesh, posterior positioning of the implant with two layer closure and routine prescription of topical and oral antibiotics post-operatively in all cases.

Key words: Mersilene mesh, Orbital implant.

\section{REFERENCES}

1. Adler RH, Furse $\mathrm{CN}$. Use of pliable synthetic mesh in the repair of hernias and tissue defects. Surg Gynaecol Obstet 1959, 108: 199-206.

2. Amis AA. Filamentous implant reconstruction of tendon defects: a comparison between carbon and polyester fibres. $J$ Bone Joint Surg (Br) 1982, 643: 682.

3. Downes RN, Collin JRO. The Mersilene mesh sling: a new concept in ptosis surgery. Br J Ophthalmol 1989, 73: 498-501.

4. Downes RN, Jordan K. The surgical management of dysthyroid related eyelid retraction using Mersilene mesh. Eye 1989, 3: 385-90.

5. Collin JRO. A Manual of Systematic Eyelid Surgery. Churchill Livingstone, Edinburgh 1986, 5: 96-100.

6. Castren JA. Experiences with different orbital implants after enucleation. Acta Ophthalmol 1963, 41: 435-44.

7. Allen JH, Allen L. A buried muscle cone implant. Arch Ophthalmol 1950, 43: 879-90.

8. Ellis OH, Levy OR. A new magnetic orbital implant. Arch Ophthalmol 1956, 56: 352.

9. Frueh BR, Felker GV. Baseball implant: a method of secondary insertion of an intraorbital implant. Arch Ophthalmol 1976, 94: 429-30.

10. Beyer CK, Albert DM. The use of fascia lata and sclera in ophthalmic plastic and reconstructive surgery. The 1980 Wendell Hughes Lecture. Ophthalmology 1981, 88: 869-86.

11. Tyers AG, Collin JRO. Baseball orbital implants: a review of 39 patients. Br J Ophthalmol 1985, 69: 438-42. 